\title{
Correction to: Effects of Exercise Training on Weight Loss in Patients Who Have Undergone Bariatric Surgery: a Systematic Review and Meta-Analysis of Controlled Trials
}

\author{
Alejandro Carretero-Ruiz ${ }^{1,2}$ (1) María del Carmen Olvera-Porcel ${ }^{3}$ • Iván Cavero-Redondo ${ }^{4,5}$ - Celia Álvarez-Bueno ${ }^{4,5}$. \\ Vicente Martínez-Vizcaíno ${ }^{4,6}$ - Manuel Ferrer-Márquez ${ }^{7}$. Alberto Soriano-Maldonado ${ }^{1,2}$ • Enrique G. Artero ${ }^{1,2}$
}

Published online: 19 August 2019

(C) Springer Science+Business Media, LLC, part of Springer Nature 2019

\section{Correction to: Obesity Surgery \\ https://doi.org/10.1007/s11695-019-04096-9}

In the original article the name of author Enrique G. Artero was misspelled. His name is correct here.

Publisher's Note Springer Nature remains neutral with regard to jurisdictional claims in published maps and institutional affiliations.

The online version of the original article can be found at https://doi.org/ 10.1007/s11695-019-04096-9

Alejandro Carretero-Ruiz alejandrocarreteroruiz@gmail.com

María del Carmen Olvera-Porcel molvera@fibao.es

Iván Cavero-Redondo ivan.cavero@uclm.es

Celia Álvarez-Bueno

celia.alvarezbueno@uclm.es

Vicente Martínez-Vizcaíno vicente.martinez@uclm.es

Manuel Ferrer-Márquez manuferrer78@hotmail.com

Alberto Soriano-Maldonado asoriano@ual.es

Enrique G. Artero artero@ual.es
Department of Education, Faculty of Education Sciences, University of Almería, Ctra. Sacramento s/n, La Cañada de San Urbano, 04120 Almería, Spain

2 SPORT Research Group (CTS-1024), CERNEP Research Center, University of Almería, Almería, Spain

3 Fundación para la Investigación Biosanitaria de Andalucía Oriental (FIBAO), Granada, Spain

4 Universidad de Castilla-La Mancha, Health and Social Research Center, Cuenca, Spain

5 Universidad Politécnica y Artística del Paraguay, Asunción, Paraguay

6 Facultad de Ciencias de la Salud, Universidad Autónoma de Chile, Talca, Chile

7 Bariatric Surgery Department, Complejo Hospitalario Torrecárdenas, Almería, Spain 